\title{
Comparison of Different Techniques of Ultrasound-Guided Fine Needle Biopsy of Liver in a Swine Model
}

\author{
Alireza Hamidian Jahromi ${ }^{1}$; David Hilton Ballard ${ }^{2}$; Reza Bahrami ${ }^{3}$; Horacio Ruben Vicente \\ D'Agostino ${ }^{3, *}$ \\ ${ }^{1}$ Department of Surgery, Louisiana State University Health-Shreveport, Shreveport, United States \\ ${ }^{2}$ School of Medicine, Louisiana State University Health-Shreveport, Shreveport, United States \\ ${ }^{3}$ Department of Radiology, Louisiana State University Health-Shreveport, Shreveport, United States \\ *Corresponding Author: Horacio Ruben Vicente D'Agostino, Department of Radiology, Louisiana State University Health-Shreveport, Shreveport, United States. Tel:+1-3186756247, Fax: \\ +1-3186755580, E-mail: hdagos@lsuhsc.edu
}

Received: December 27, 2014; Revised: February 15, 2015; Accepted: March 10, 2015

\begin{abstract}
Background: The quality of liver biopsy specimens obtained with different fine needle biopsy (FNB) techniques has not been compared. Objectives: This study was performed to evaluate the diagnostic quality of three different liver FNB biopsy techniques.

Materials and Methods: Two sequential biopsy series were performed on piglets. Three biopsy techniques were compared: capillary-FNB, core-FNB (CFNB) and vacuum-assisted CFNB(VACFNB) in a swine model. Initially, 30 liver biopsies were performed (ten for each technique). The cellularity and quantity of blood in specimens were measured and compared. In the second series, 54 additional biopsies using CFNB and VACFNB techniques (27 each) in a separate piglet were evaluated in the same fashion.

Results: In the first series, cellularity and blood levels were significantly lower in capillary-FNB compared with $\mathrm{CFNB}(\mathrm{P}<0.001$ and $\mathrm{P}=0.011$, respectively). There was no significant difference between CFNB and VACFNB in cellularity and blood ( $\mathrm{P}=0.15$ and $\mathrm{P}=0.1$, respectively). In the second series, cellularity was significantly higher in CFNB compared with VACFNB $(\mathrm{P}<0.001)$ with no significant difference in blood $(\mathrm{P}=0.5)$.

Conclusions: Among these three different FNB techniques, CFNB technique provided the greatest cellularity. Capillary-FNB technique was inferior among all with the lowest quality of obtained material for cytopathological interpretation.
\end{abstract}

Keywords: Fine Needle Biopsy; Fine-Needle Aspiration; Liver; Core Needle Biopsy

\section{Background}

Although aspiration needle biopsy of the liver was first introduced by Poul Iversen and Kaj Roholm in Copenhagen just before the Second World War (1938), the acceptance of such technique as a clinically useful method for biopsy of solid organs, rather surprisingly, took almost half a century (1). Accidental renal material obtained by physicians attempting to do liver biopsies led Robert Kark to wonder whether the technique could be deliberately applied to the kidney (2). Introduction of new needles, application of new technologies to biopsy devices and improving biopsied tissue preservation are examples of the attempts made to improve the diagnostic yield and accuracy of needle biopsies (3). Although improvements in imaging technology have contributed to early detection, precise localization and characterization of lesions, development of an ideal biopsy technique is far from being achieved.

\section{Objectives}

This study was performed to evaluate the diagnostic quality of three different liver fine needle biopsy (FNB) techniques.

\section{Materials and Methods}

Following an institutional review board (IRB) and Animal Care and Use Committee (ACUC) approval, we compared three different techniques of ultrasound (US)-guided (FNB): capillary-FNB, core-FNB (CFNB) and vacuum-assisted CFNB (VACFNB) in a swine model. The study consisted of two sequential biopsy series in two separate piglets (70 kg Hanford miniature swine) under general anesthesia and endotracheal intubation. All biopsies were performed under US guidance (GE 3200, 3.5 $\mathrm{MHz}$ transducer; General Electric Company, Fairfield, Connecticut) by an experienced interventional radiologist using a subcostal approach and a 25-gauge spinal needle (BD Spinal Needle; BD Medical, Franklin Lakes, New Jersey). Each biopsy was obtained $1 \mathrm{~cm}$ apart from each other in three horizontal lines along the periphery of the left lobe of the liver away from identifiable intrahepatic vessels. Ten specimens were sequentially obtained using each of the three biopsy techniques.

\subsection{Techniques}

Capillary-FNB: The needle along with the stylet was advanced $4 \mathrm{~cm}$ into the liver parenchyma. The stylet was

Copyright ( 2015, Kowsar Corp. This is an open-access article distributed under the terms of the Creative Commons Attribution-NonCommercial 4.0 International License (http://creativecommons.org/licenses/by-nc/4.0/) which permits copy and redistribute the material just in noncommercial usages, provided the original work is properly cited. 
Hamidian Jahromi A et al.

removed and the needle was left in place for 30 seconds. After 30 seconds, the needle was removed while covering the needle hub with the tip of the index finger to maintain the specimen within the needle lumen. The needle content was transferred onto a glass slide by gently blowing $5 \mathrm{~mL}$ of air with a syringe.

CFNB: The needle along with the stylet was advanced $4 \mathrm{~cm}$ into the liver parenchyma. The stylet was removed and the outer end of the needle was held by the thumb and index fingers. The needle was thrusted 5 times (5 passes) with $2 \mathrm{~cm}$ length for each pass. The same technique for capillary-FNB was performed to transfer the obtained material from the needle to the slide.

VACFNB: The same steps for CFNB were performed up to the point of stylet removal. After removing the stylet, the needle was attached to a $20 \mathrm{~mL}$ syringe, filled with $5 \mathrm{~mL}$ air through a connecting tube. A $5 \mathrm{~mL}$ negative pressure was applied and the piston was maintained in a withdrawn position while thrusting the needle as the CFNB technique was performed. To prevent a sudden spraying of the contents of the needle over the walls of the syringe, care was taken to release the piston before the needle was withdrawn. The same technique for placing the obtained material, using $5 \mathrm{~mL}$ of air previously loaded in the syringe, was applied.

In the first initial series, the specimens from each technique were placed on two pre-numbered slides (one air dried and one fixed with a cytological spray fixative). The air-dried and the fixed slides were stained with Diff Quick and Papanicolaou method, respectively (Figure 1).
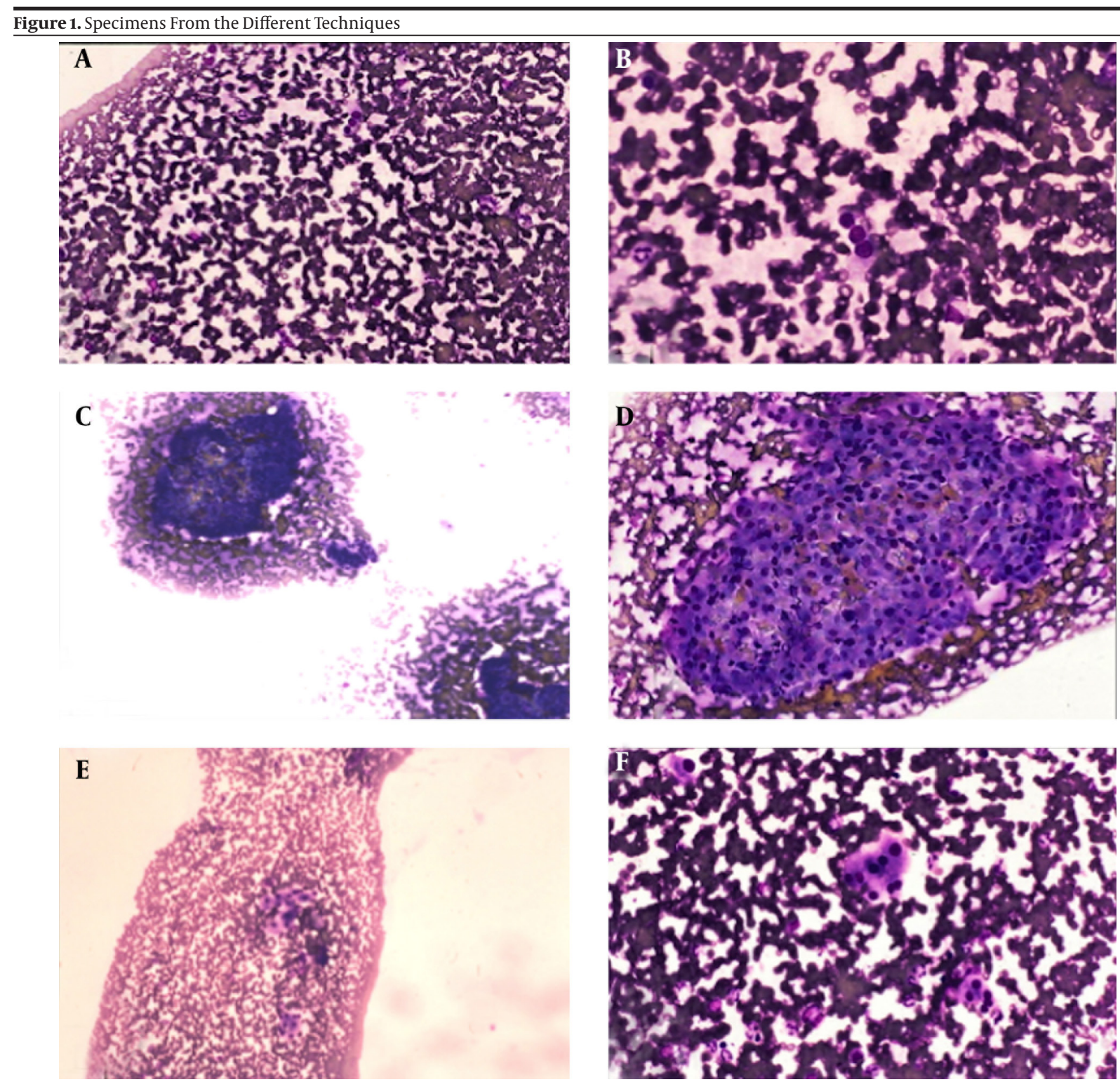

A and B, capillary fine needle biopsy (Capillary-FNB) technique with low [x40] and high [x100] magnification, respectively; C and D, core FNB (CFNB) technique with low [x40] and high [x100] magnification, respectively; and $\mathrm{E}$ and $\mathrm{F}$, vacuum-assisted core FNB (VACFNB) technique with low [x40] and high [x100] magnification, respectively. 
Hamidian Jahromi A et al.

The quantity of cellularity and blood of the obtained specimens were the two parameters measured from each biopsy specimen. Specimens' adequacies regarding cellularity ( 0 - 4 scale) and blood levels ( 0 - 4 scale) were evaluated by a cytopathologist blinded to the biopsy method used. Statistical Analysis System (SAS-8) software and Kruskal-Wallis and Wilcoxon tests were used for the statistical analysis.

Upon analysis of the initial first series, a larger sample size was needed to compare CFNB with VACFNB techniques. A power analysis revealed that a sample size of 54 for both CFNB and VACFNB techniques (27 each) was needed to reach statistical significance. The 54 additional biopsies using the CFNB and VACFNB techniques (27 each) were performed in a separate piglet using the same technique and conditions described previously.

\section{Results}

Cellularity and blood levels were significantly lower in capillary-FNB compared with CFNB $(\mathrm{P}<0.001$ and $\mathrm{P}=0.011$, respectively). However, there was no significant difference between CFNB and VACFNB for cellularity and blood ( $\mathrm{P}=$ 0.15 and $\mathrm{P}=0.1$, respectively) (Table 1 ). CFNB and VACFNB techniques in both cellularity and blood had a P value $>$ 0.05 (lack of difference could be due to small sample size). Therefore, we performed the additional series of experiments with a larger sample size comparing these two techniques (Table 1). In the second series, the cellularity was significantly higher in CFNB compared with VACFNB group ( $P$ $<0.001)$. However there was no significant difference in blood between the two groups $(\mathrm{P}=0.5)$.

Table 1. Biopsy Specimen Data From Different Fine Needle Biopsy Techniques in the Two Piglets ${ }^{\text {a }}$

\begin{tabular}{lcccc}
\hline Series/Piglet & $\begin{array}{c}\text { Biopsy } \\
\text { Technique }\end{array}$ & $\begin{array}{c}\text { Number of } \\
\text { Biopsies }\end{array}$ & Cellularity $^{\mathrm{b}}$ & Blood $^{\mathrm{b}}$ \\
\hline First/Piglet-1 & Capillary FNB & 10 & $0.3 \pm 0.48$ & $1.4 \pm 0.52$ \\
\hline First/Piglet-1 & CFNB & 10 & $2.8 \pm 0.35$ & $2.0 \pm 0.0$ \\
\hline First/Piglet-1 & VACFNB & 10 & $2.2 \pm 0.95$ & $2.0 \pm 0.47$ \\
\hline Second/Piglet-2 & CFNB & 27 & $2.45 \pm 0.9$ & $2.2 \pm 0.5$ \\
\hline Second/Piglet-2 & VACFNB & 27 & $1.48 \pm 1.0$ & $2.1 \pm 0.6$ \\
\hline
\end{tabular}

a Abbreviations: CFNB, Core FNB; FNB, fine needle biopsy; VACFNB, vacuum-assisted core FNB (Core + suction FNB).

$\mathrm{b}$ Values are presented as Mean \pm Standard Deviation.

\section{Discussion}

Our animal experiment substantiated a simple technique for obtaining diagnostic specimens for cytopathology. The cellularity and limited blood in the samples allows the cytopathologist to have adequate samples for interpretation $(4,5)$. Additionally, the CFNB technique described uses standard fine needles and is performed by a single operator using only one hand. Therefore, it is a high diagnostic yield method with broad application and little complexity. These benefits support the use of this technique for biopsy of localized lesions in easy to access or challenging locations.

There is conflicting terminology among FNB techniques. It is beyond the scope of this article to clarify FNB vocabulary. Conceptually, capillary FNB is simply inserting the needle within the tissue, allowing the tissue pressure to push its cells into the needle lumen ('capillary pressure'). A 'coring' FNB is a technique in which a thrust is applied to the needle to cut tissue, which enables tissue fragments to get into the needle lumen. However, there is a wealth of FNB literature that uses these terms indistinctly (e.g. 'capillary-', 'aspiration-', and 'coring-' sampling) (4-9).

Reports have shown that sonographic assisted biopsies of abdominal organs with the automatic Autovac biopsy system (an example of newly developed full-cut CFNB) yield high-quality biopsy cylinders that enable reasonable histologic diagnoses in a high percentage of cases. However, there are hemorrhagic complications in $2.5 \%$ of biopsies and severe hemorrhages in 1.2\% (10). Large amount of data on complication rates after percutaneous biopsies are available almost exclusively for FNB, and those rates vary considerably $(4,9,11)$.

One of the study limitations was performing the biopsy in a normal animal liver. An assessment of the techniques used on diverse pathologic tissues/organs with different degrees of fibrosis and vascularity may provide useful information for obtaining diagnostic samples. CFNB is used by some pathologists for biopsies of palpable lesions (4, 5 ) as well as our institution as a routine preferred FNB technique.

The quality of biopsy specimens obtained with different biopsy techniques have not been adequately addressed before. Furthermore, the criteria for judging the quality of specimens are very different and not comparable. For FNBs, depending on the organ being punctured, usable tissue can be obtained in $70 \%$ to $90 \%$ of cases $(4,9,11-13)$. In situations where the diagnostic yield of FNB is not optimal (i.e. lung biopsies), repeating FNB could also potentially increase the yield without significant increase in complications (11). In a recent study from Iran, Alamdaran et al. (11) proposed ultrasound guided CFNB of the liver even in cases with atypical hemangioma as a safe and reliable technique when assessing patients with focal hepatic lesions (11).

Close collaboration between radiologist and pathologist is an integral component of any imaging-guided biopsy program, which ultimately aims at making an important judgment on presence or absence of a malignant tumor at the site.

Among these three different FNB techniques, CFNB technique provided higher amount of cellularity. CapillaryFNB technique was inferior among all with the lowest quality of obtained material for cytopathological interpretation. To confirm the presented data, future clinical comparative studies are required.

\section{Acknowledgements}

The authors would like to thank Dr. Elba Turbat-Herrera 
for slide interpretation, and Talicia Tarver who provided us editorial assistance.

\section{References}

1. Roholm K, Iversen P. Changes in the Liver in Acute Epidemic Hepatitis (Catarrhal Jaundice) Based on 38 Aspiration Biopsies*. Act Pathol Microbiol Scand . 2010;16(4):427-42.

2. Cameron JS, Hicks J. The introduction of renal biopsy into nephrology from 1901 to 1961: a paradigm of the forming of nephrology by technology. Am J Nephrol. 1997;17(3-4):347-58.

3. Rockey DC, Caldwell SH, Goodman ZD, Nelson RC, Smith AD, American Association for the Study of Liver D. Liver biopsy. Hepatology. 2009;49(3):1017-44.

4. Kashi Z, Torabizadeh Z, Akha O, Yaseri A, Shahidi MH, Mokhtare M. Combination of aspiration and non-aspiration fine needle biopsy for cytological diagnosis of thyroid nodules. Caspian J Intern Med. 2011;2(4):299-303.

5. Cajulis RS, Sneige N. Objective comparison of cellular yield in fine-needle biopsy of lymph nodes with and without aspiration. Diagn Cytopathol.1993;9(1):43-5.

6. Briffod M, Gentile A, Hebert H. Cytopuncture in the follow-up of breast carcinoma. Acta Cytol. 1982;26(2):195-200.
7. Zajdela A, Zillhardt P, Voillemot N. Cytological diagnosis by fine needle sampling without aspiration. Cancer. 1987;59(6):1201-5.

8. Arcari A, Anselmi E, Bernuzzi P, Berte R, Lazzaro A, Moroni CF, et al. Primary pancreatic lymphoma. Report of five cases. Haematologica. 2005;90(2):ECR09.

9. Tauro LF, Lobo GJ, Fernandes H, George C, Aithala PS, Shenoy D, et al. A Comparative Study on Fine Needle Aspiration Cytology versus Fine Needle Capillary Cytology in Thyroid Nodules. Oman Med J. 2012;27(2):151-6.

10. Riemann B, Menzel J, Schiemann U, Domschke W, Konturek JW. Ultrasound-guided biopsies of abdominal organs with an automatic biopsy system. A retrospective analysis of the quality of biopsies and of hemorrhagic complications. Scand J Gastroenterol. 2000;35(1):102-7.

11. Alamdaran A, Esmaeilzadeh A, Nourouzi HR, Mohajeri HR, Yazdani AA. Ultrasound-guided core needle biopsy of liver hemangiomas: three-year experience. Iran J Radiol. 2007;4(4):255-8.

12. Dabirmoghaddam P, Sharifkashany S, Mashali L. Ultrasoundguided fine needle aspiration cytology in the assessment of cervical metastasis in patients undergoing elective neck dissection. Iran J Radiol. 2014;11(3):e7928.

13. Yazar E, Secik F, Yildiz P. Does Repeating CT-Guided Transthoracic Fine Needle Aspiration Increase Diagnostic Yield and Complication Rate? A Single Institution Experience. Iran J Radiol. 2013;10(2):56-60. 